\title{
Questioning 20th Century Assumptions About 21st Century Music Practices
}

\author{
Janice Waldron \\ University of Windsor
}

In this essay, I critique and critically reflect upon two questions derived from Action Ideal VIII of the MayDay Group: "We commit to understanding the wide range of possibilities and the limitations that technology and media offer music and music learning." Before we can address the "how," it is necessary to know the "why," which I offer here. This includes questioning dichotomies based on beliefs that either no longer hold true and/or are based on a presumptive fallacy-first, that making music in the 21st century is an "either/or" proposition-i.e. one either makes music acoustically or digitally but not both, and second, an implicit belief that hands-on acoustic face-to-face music making is always preferable to making music digitally-either by one's self or with others through technological mediation - for various reasons. I conclude with a discussion of the impact that corporate power on the Web has and continues to have on music making, and by extension, music learning, in the 21st century.

Keywords: "bi-contextuality," "long tail" musics, Web as "sociotechnical construct," Web 2.o, online music communities, data mining.

$\mathrm{T}$ he rapid pace of technological change over the last decade, particularly in relation to social media and network connectivity, has deeply affected the ways in which we interact socially (and musically) among individuals, groups, and institutions to the point that it has become difficult to grasp what it would be like to lose access to this everyday aspect of modern life. To paraphrase William Gibson, "the future is with us now, only spread around thinly." Although Gibson wasn't referencing music (and music making) specifically, his words aptly describe current 21st century music making (and music learning and teaching) practices. Like the fish that can't perceive the water in which it swims, neither can we easily comprehend the importance of digital technology and communication in our daily lives. Because of technology's all-encompassing pervasiveness, it is also 
not easy to recognize the implications of the challenges it brings either. Which brings me to the point of this essay, the purpose of which is to critique the below two questions derived from MayDay Action Ideal VIII:

1) Given the pervasive use of digital technology and communication, how do we integrate alternatives; for example, acoustic, live, hands-on, face-toface, and culturally situated interactive music making, as an essential component of human cooperation and community?

2) How can we use contemporary media and technology to empower people to assert their own local and personal identities, and to critically resist the onslaught of global marketing and branding aimed at their particular demographic?

My initial (and short and cynical) response to both questions above is: 1) we can't, 2) why would we?, and, 3) it is already here and happening but we are not aware of it (and to which I think Gibson would agree). ${ }^{2}$ However, flippant answers aside, the larger implicit "meta" concern both inferred in and underlying the above questions can be explained by what communications scholar Henry Jenkins believes is "the moral panic about digital technology [that often is] a case of adults not understanding a world that has not been a part of their childhood experiences" (in James 2014, xviii). Although Jenkins writes from his perspective as a new media educator, his thoughts here also encapsulate the fear (and/or naiveté) surrounding similar issues in music education. As is often the case with new "things" in music education-ideas and/or technologies-by the time most of us in academia are aware of them (and, more importantly, the effects they have on what we do), not only is the "horse already out of the barn," it is usually long gone and racing over the hills into the next county. 3

While what Jenkins identifies as the "moral panic of digital technology" is the "macro" concern/assumption underlying the above questions, within both questions also lie several additional "micro" assumptions that need further unpacking. I explain and offer my critique of each below, beginning with Question One and continuing on to Question Two.

\section{Critique: Question One}

Given the pervasive use of digital technology and communication, how do we integrate alternatives; for example, acoustic, live, hands-on, faceto-face, and culturally situated interactive music making, as an essential component of human cooperation and community?

Waldron, Janice. 2018. Questioning $20^{\text {th }}$ century assumptions about 21 st century practices. Action, Criticism, and Theory for Music Education 17 (1): 97-113. doi:10.22176/act17.1.97 
First, embedded in this question is a dichotomy based on beliefs that either no longer hold true and/or are based on a presumptive fallacy-that is, that making music in the 21st century is an "either/or" proposition-i.e. one either makes music acoustically or digitally but not both. Second, also implicit here is a belief that hands-on acoustic face-to-face music making is always preferable to making music digitally-either by one's self or with others through technological mediationfor various reasons, the presumption being that making music acoustically faceto-face is the only way to do so in a "culturally appropriate" manner. In other words, "culturally situated interactive music making" is not possible if the music making in question is technologically mediated in any way. There are many examples that demonstrate that this: 1) simply is not the case, and, 2) is not necessarily a dichotomy either. I will illustrate this and the third point below later in this paper through the narrative of a musician with a dual but fluid digital/acoustic musical identity.

Third, what is also obfuscated here is that genre is tied directly to context, also indelibly linked to acceptable and appropriate performance practice in said genre. For example, up until the last decade or so, context in music always meant an offline, geographical "place" embedded in a physically situated culture. But now, there are many existing music genres (along with their respective corresponding cultures) that are made, composed, performed, and located online and/or "in the cloud." 4 In those musics, the online location is a fundamental and integral part of how and why the musics in question are made (either by individuals or through collaboration with others), performed, shared, and enjoyed. 5 Furthermore, and related to this, is that the above question inherently privileges acoustic music making as "better" than digital music making because it implies that what people experience when making digital music is not representative of an "authentic" culture nor does it induce or result in the same kind of "flow" state as it does for people who make music acoustically. Based on the number of people who passionately participate in making/producing digital musics, one must conclude that neither of these assumptions is true.

Last, this question ignores the impact that the Web (and more specifically Web 2.0 applications), has had on the growth of and access to acoustic vernacular musics that exist both inside and outside of the mainstream - what can be referred to as "long tail" ${ }^{6}$ musics (after Anderson 2006). In many of these genres, people would much prefer to play together or learn music face-to-face, but due to geographical or physical limitations cannot-so the Web becomes the second best

Waldron, Janice. 2018. Questioning $20^{\text {th }}$ century assumptions about 21st century practices. Action, Criticism, and Theory for Music Education 17 (1): 97-113. doi:10.22176/act17.1.97 
thing, or, in the words of a participant from an earlier study of mine, "better than nothing" (Waldron and Hopper 2016). Communications researchers Rainie and Wellman explain this phenomenon from a larger and more general perspective, stating that:

Critics used to worry that the Internet would be an inadequate replacement for human contact because hugging a computer screen is less satisfying than hugging a friend. In fact, evidence shows that Internet communication technologies supplement-rather than replace-human contact. People will make do with electronic contact if they cannot be together in person. (Rainie and Wellman 2012, 144)

Although Rainie and Wellman do not mention music (or music making) specifically in the above quote, research suggests that their words are directly applicable to music and music making and the effect of the Internet on the same (Kruse and Veblen 2013; Waldron 2016, 2013b). They also make another good point-that is, that Web interactions can, and often do, supplement offline ones. Indeed, research shows that groups of people who participate in online communities tend to have more contacts socially offline with others from their affinity groups than those who do not. As Daniel Miller says (2011):

Critical to this observation is the question of whether people who interact online do so at the expense of offline interaction. Hampton and Wellman's (2003) research suggests that the group who heavily networks online tends to also extend their social interactions offline, in contrast to those who lack online facilities. (183)

To put it simply, "Facebook is not a patch on the real thing" (Miller 2011, 24).

In a context such as those found in online music communities this has significant implications. First, belonging to an online community serves to "grow" the music in question because it allows people to locate, share content-most often user-generated-and discourse with like-minded musicians; second, Web communities also function to guide people who meet online towards an offline setting where they can then meet and play music together acoustically in a geographically placed community setting (for example, see the traditional music website, www.thesession.org). I offer two examples from my own research further on in this paper as illustration.

Example Number One: Dual digital/acoustic musical identity, the case of Marco With this first example, I illustrate that 21st century music making is not an either/or proposition-i.e. that one either makes music digitally or acoustically but

Waldron, Janice. 2018. Questioning $20^{\text {th }}$ century assumptions about 21st century practices. Action, Criticism, and Theory for Music Education 17 (1): 97-113. doi:10.22176/act17.1.97 
not both-through the narrative of Marco,7 a fifth year undergraduate BA Music Education student at my institution, and his story is consistent with literature on performers with multiple musical identities (Burnard 2012, Pitts 2012). ${ }^{8}$ Marco is a participant in a qualitative ethnographic case study I've undertaken on the role of "informal music learning practices 2.0" 9 in the music learning of undergraduate jazz/pop music education music majors at my university. Even though he isn't a jazz/pop major-and which made him an outlier in the research-I included Marco because he is an active digital instrumental hip hop producer ${ }^{10}$-currently signed with two recording labels-and he is also a classically trained pianist with his Royal Conservatory Grade 8. Marco's narrative is intriguing because he is fluently bi-musical in both genres and also uses skills acquired from each genre to negotiate musical challenges in the other. He is also what I have identified and defined as "bicontextual," which I will explain further below.

Marco first began studying classical (Royal Conservatory) piano as a six yearold, enrolled in lessons by his parents. As is the normal practice with Conservatory lessons, his teacher stressed visual learning through written Western notation over aural/oral and/or observational learning. As Marco became older however, he wanted to learn to play pop songs he'd heard on the radio, and asked his teacher if they could work on them during Marco's lessons. Unfortunately for Marco (or fortunately, depending on one's point of view), his teacher was unwilling to do so and flatly dismissed the possibility in no uncertain terms. Frustrated by his teacher's lack of enthusiasm, Marco began "picking out" pop tunes by ear on the piano. He says that now, when learning classical piano repertoire, he listens to recordings first to aurally learn the piece he's chosen; he then uses written notation to "fill in the blanks." He attributes his ability to do so because of his earlier experiences learning pop tunes by ear but not to his Conservatory training.

Marco was initially exposed to hip hop music when he began playing high school basketball as a 9th grader; it was always played loudly at and during practices. By that time, he was already a self-taught proficient aural/oral learner from playing pop songs on the piano, and, because of his Royal Conservatory training, had a strong music theory/classical performance background as well. Marco explained that knowledge of both of the latter is "highly prized" among hip hop producers because of the musical skills and knowledge that both bring to a producer in the hip hop genre. ${ }^{11}$

Marco initially connected online with other hip hop producers through the numerous Web hip hop communities, but he credits his "discovery" to Instagram, 
because the site allows him to upload 15 second digital GIFs of his "beats" there to share with others (https://www.instagram.com/marco_cian/). This led to Marco's collaborating (or "collab" in hip hop slang) with a well-known hip hop producer in Los Angeles who contacted Marco after hearing his work on Instagram. Although the two have now done extensive work together, they have yet to meet offline. Further, it was through this producer's contacts that Marco was then introduced to two New York producers (also online), and which lead to his contracts with the two labels with whom he is now signed. However, digital "beat producing" in Marco's life also takes place in offline contexts like the University; Marco and two of his music major friends often get together with their computers to share and compare each other's compositions in practice rooms at the University.

As much as Marco enjoys "producing beats"12 however-he described himself as being "consumed" with doing so-he also enjoys jamming on acoustic piano with his friends, some of whom are in the jazz program at the University. So, when Marco jams in jazz, he does so acoustically and offline, often at a University friend's basement with other musicians. Thus Marco is bi-musical (tri-musical, actually, including his jazz "chops") as well as "bi-contextual"; he is equally comfortable making music with others both digitally online and acoustically offline.

\section{Example Number Two: Online/offline convergent music communities}

Research on online music communities illustrates how question number one also does not consider the impact that Web 2.0 applications have had on the growth and spread of vernacular musics. In addition to my own work (Waldron 2016, 2013a, 2013b, 2011), seminal studies from music education scholars in this area include research from Salavuo (2006, 2008), Salavuo and Hakkinen (2005), Partti and Karlsen (2010), Paparo and Talbot (2014), and Michealise and Parrti (2015). Related to this body of literature are music education and ethnomusicological studies on social media, community, and music learning and teaching (Palmquist and Barnes 2015, Blanton 2016, Cawley 2013, O’Flynn 2015, and Webster and Brewer 2014).

For specific illustrations of how question number one ignores the impact that Web 2.0 applications have had on the now wide spread availability of non-mainstream, vernacular, or "long tail" musics (Strachan, 2010), I draw on examples from my own research of two contrasting online communities-the Online Academy of Irish Traditional Music (OAIM) (www.oaim.ie) and the Banjo Hangout

Waldron, Janice. 2018. Questioning $20^{\text {th }}$ century assumptions about 21 st century practices. Action, Criticism, and Theory for Music Education 17 (1): 97-113. doi:10.22176/act17.1.97 
(BH) (www.banjohangout.org) (Waldron 2016, 2013b). The OAIM is an intentional online music community, as it is a for-profit school established with the specific purpose of providing high quality Irish traditional (IrTrad) music instruction online to people who don't have physical access to local IrTrad teachers and instruction, while the $\mathrm{BH}$ is an open-access website/online community founded on the idea of sharing and connecting with others to discuss "all things" banjo. Both sites have members from all over the world, and although OAIM members pay to have direct site access (as opposed to the $\mathrm{BH}$, where membership is free), both sites are based on the idea of a "culture of connectivity"13 (after Van Dijck 2013). In other words, embedded links to other useful online media sources like YouTubes and blogs are integral to both sites' usefulness for members and for both sites' successes in terms of growth. Not only do both sites function as communal "resource hubs" for their respective musics and instruments, they also serve to guide and connect members who meet online to places to meet and play together acoustically offline. In other words, the online community converges with the offline one, and I offer two examples from the BH study. Here I explain how BH participant Marc Nerenberg

discovered one fellow Hangout member-a newbie-through an online forum discussion whom, to their mutual surprise, lived a few blocks away from Marc in Montreal, Quebec. They arranged to meet with their banjos at a nearby mall, whereby Marc, as an experienced musician and banjo player, helped the newbie with tips and advice as both sat and played amongst hungry shoppers in the mall's food court. (Waldron 2013b, 97)

BH participant Link Miller's narrative serves as an example of an online/offline/convergent narrative that has come full circle; after discovering the $\mathrm{BH}$ online, Link found a regular offline jam listed on it located in his hometown of Melbourne, Australia, and which he began attending regularly. Playing offline at the Melbourne jam led Link right back to the $\mathrm{BH}$ :

We [meaning his fellow jammers] meet once a week for the sessions, so I get to pick someone's brain [in person] once a week. But having the Hangout to be able to get tunes online -sometimes I get very excited about a tune-I fly home from the session [saying to myself], 'I've gotta learn Kitchen Girl, I've gotta learn Kitchen Girl' so it's straight in [to the BH] and on my way. (Waldron 2013b, 97)

Related to this is the idea that online communities act as "substitute" offline communities when the real thing isn't available, a phenomenon explained earlier by Rainie and Wellman; that is, that people will "make do" with connecting

Waldron, Janice. 2018. Questioning $20^{\text {th }}$ century assumptions about 21st century practices. Action, Criticism, and Theory for Music Education 17 (1): 97-113. doi:10.22176/act17.1.97 
through the Web rather than in person if what they need/want isn't available locally (2012). Participants from both my BH study and my OAIM research gave examples of this. First, these words from BH participant Bret Young:

The site [the BH] served very much as a substitute for a real-life old time music community, passing along information and knowledge, and encouraging me to start playing myself. Since it is hard to find strong, active old time music communities in most cities, including Columbus, Ohio [where Bret lives], having such daily interaction with other old time banjo players on the Banjo Hangout probably kept me interested enough to eventually get myself a banjo and look for a teacher. (Waldron 2013b, 98)

Here is a similar and poignant sentiment expressed by $\mathrm{BH}$ participant David Healy:

Playing bluegrass is a communal experience, at least traditionally. Unfortunately, I know few people in Los Angeles who share my love for this music. The Internet helps me to connect with people who do and fills what would otherwise be a musical vacuum. (Waldron 2013b, 99)

Finally, BH participant Elmer Fudd (a pseudonym), whose health prevented him from leaving his home to play banjo with others and who used the Internet exclusively to learn Old Time music, shared the following:

The only downside to learning exclusively via the Internet is missing out on the relationships and bonds that form as a result of 'live' jam sessions and lessons. (Waldron 2013b, 99)

Participants from my OIAM study also reported that learning music in an Internet community was a distant second when compared to playing live with others. OAIM participant Marlene lives in Zurich, Switzerland where there is no live IrTrad music or players available close to her. But she noted that:

I think it's fantastic [the OAIM] for what you get. It's not ideal-but it's a lot better than nothing. I'd have nothing [meaning IrTrad] when I was in Zurich. (Waldron and Hopper 2016, 9)

Because all of the OAIM participants expressed sentiments similar to Marlene's, I therefore concluded that although the

OAIM study participants stressed how much face-to-face music learning situated within the culture from whence it came was the "best possible" way to learn IrTrad, [they] also stressed that the Internet afforded them access to a music culture not previously possible before the advent of the Web. In other words, music learning in online participatory culture did not trump playing and learning in real time with others in a physical location; rather, Internet learning was seen as an

Waldron, Janice. 2018. Questioning $20^{\text {th }}$ century assumptions about 21st century practices. Action, Criticism, and Theory for Music Education 17 (1): 97-113. doi:10.22176/act17.1.97 
important addition to playing music with friends and/or a teacher. (Waldron 2016)

It is clear that, although the Internet does play a significant role for people who want to learn vernacular acoustic musics, it does not replace live acoustic music making with others. What the Internet does do however is enlarge the availability and scope of musics that lie outside of peoples' local geographical spheres; it also connects them to others who share similar musical interests. I continue in the next section of this essay with a critique of Question Two.

\section{Critique: Question Two}

How can we use contemporary media and technology to empower people to assert their own local and personal identities, and to critically resist the onslaught of global marketing and branding aimed at their particular demographic?

This question begs deconstructing because it really addresses two distinct and separate issues: 1) the idea that we (as a small group of music educators) can empower people to retain local and personal identities, and that, 2) as a small group of music educators, we have some power and influence in resisting global marketing and corporate power. I'll start backwards by addressing the second part of the question and then discuss the first.

As worded, the second portion of this question presents the issue of corporate power on the Web and resistance to it as a duality. But it is not; rather, because the Web is a "sociotechnical construct," in which "content, technology, and users are completely intertwined with one another," resisting corporate power and branding mechanisms is much more complicated than question two implies (Van Dijck 2013, 28). Just "pushing back" (or "resisting") could be compared to poking one's finger in a balloon filled with water-it makes a small dent, but remove the finger and the balloon returns to its natural shape.

According to Van Dijck (2013), the only way we can address power issues in the technological ecosystem that is the Web is to "analyze technology, users, and content in close alignment, [and] highlight[ing] platforms as socioeconomic structures" (28). Although there are platforms belonging to and run by grass roots nonprofit political/social activists that counter traditional power structures (the ACT website comes to mind as one example here), the majority of Web platforms are owned and operated by governments and businesses. This means that we must

Waldron, Janice. 2018. Questioning $20^{\text {th }}$ century assumptions about 21st century practices. Action, Criticism, and Theory for Music Education 17 (1): 97-113. doi:10.22176/act17.1.97 
therefore continually question, scrutinize, and critically think about both the latters' respective business models because of the effect that those have on the system as a complete "sociotechnical construct," as well as teaching others to do the same (28). It is only when we get to this point that we can then begin to produce actions that create meaningful results. As Castells asserts, the "shaping of Web 2.0 [takes place through] the clash between users asserting communicative and creative freedom and owners curbing users' newly acquired technological power" (in Van Dijck 2013, 27). Thus, gaining knowledge of a platform's business model (and its underlying agenda) is the only way to gain some degree of user empowerment; teaching people to question where, why, how, and who stands to gain from whom they buy their "stuff," share information with, and obtain information from has always been understood as the basis for critical thought. This is not a new idea. So, I think it is safe to conclude that we must teach awareness of who stands to profit from our Internet transactions along every step of the way, which is even more important now that a good deal of "life" takes place on or is done through the Web. Add in the proliferation of large-scale Internet "big data" mining, in which gathering and sharing personal data without users' knowledge or permission is now routine, and teaching people about Internet awareness-as well as the impact that doing transactions on the Web can have on their lives-becomes even more imperative (Schneier 2015). So as music educators, because we play a key role in shaping our students' future musical lives and/or careers, we have an obligation to our students to make sure that they develop a critical awareness of the how the above impacts the musical choices and decisions they make both now and in the future.

Issues surrounding "big data" mining also brings me to the first half of question two: "how can we use contemporary media and technology to empower people to assert their own local and personal identities?" Although it at first seems unrelated to empowerment, for musicians (which includes music learners and teachers), knowledge of how data mining works-because it is always intertwined with corporate power and interests-on the Web is paramount, as futurist Jaron Lanier explains in his somewhat grim narrative of the power struggle between musicians and Web platforms below (2013). What he describes here is data mining done for the purposes of obtaining musical property without the knowledge of the musician whose property it is:

Third-party spy services like a social network or a search engine will invariably create persistent wealth from the [musical] information that is copied, [that is] the recordings. A musician living a real-time career, divorced from what used to

Waldron, Janice. 2018. Questioning $20^{\text {th }}$ century assumptions about 21 st century practices. Action, Criticism, and Theory for Music Education 17 (1): 97-113. doi:10.22176/act17.1.97 
be commonplace levees like royalties or "mechanicals," [CDs, records, etc.] is still free to pursue reputations and even incline (through live gigs, T-shirts, etc.), but no longer wealth. The wealth goes to the central server. (Lanier 2013, 51)

On a positive note, however, promoting and asserting local and personal musical identities has become much easier in the 21st century, if one's purpose is to share one's music with others but not make a living from it. This is undoubtedly a good thing, particularly in cases of spreading and preserving acoustic "long tail" musics and traditions discussed earlier, and Lanier does offer the (somewhat hopeful) caveat that "a remarkable number of people do get attention and build followings for their music online" (23). For example, music education scholar Christopher Cayari's (2016, 2011) work illustrates Lanier's point on how massive fan cultures develop online through YouTube, as artists bypass what used to be "traditional" distribution methods controlled by the music industry; he further explains that how and what those artists learned in the process (both musically and technically) serve as useful examples for how music educators can use YouTube as a creative vehicle with their students in school music learning and teaching contexts.

However, as Lanier points out-and as Cayari's work confirms-few artists are able to parlay that fandom into a musical living - and those that do must conform their musics along with their musical identities to what those in the global Web corporate world think will be most profitable:

Musicians seeking to make a living are goaded by the preferences of the marketplace into becoming symbols of a culture or counterculture. The countercultural ones become a little wounded, vulnerable, weird, dangerous, or strange ... multitudes of people want nothing more than to be able to play music for a living. We know this because we see their attempts online. There's a constant re-tweeting of the lie that there's a substantial new class of musicians succeeding financially through Internet publicity. Such people do exist, but only in token numbers $(2013,51)$.

So, there is no easy and straightforward solution to both of the complicated issues presented in Question Two; however, I believe that educating both ourselves and our students on the complex intricacies of how the Web works is the first place to begin. Information-aligned with critical thought-is power (and empowerment). After that comes informed action.

\section{Conclusion}

Waldron, Janice. 2018. Questioning $20^{\text {th }}$ century assumptions about 21st century practices. Action, Criticism, and Theory for Music Education 17 (1): 97-113. doi:10.22176/act17.1.97 
Social networking and social media sites have made the disjunct between school music and out-of-school music genres - which has always existed - more glaringly obvious than ever before. Directly connected to this dichotomy are issues of: 1) how people learn, teach and do music, 2) what genres those musics are, and, 3) where those musics are made, learned, and performed, be it in an online context, an offline one, or a convergence of the two. The last point further complicates outdated notions and justifications of what is "right," or "good" in music performance, as performance practice in any genre is intertwined with how and where the genre is learned and taught.

Ignoring all three of the above points undermines music education's relevance in terms of product, process, and delivery in general but in school music specifically. At the time of this writing, social media platforms YouTube and Instagram deserve special attention in terms of bridging the divide between formal music and out-of-school contexts for music learning and teaching for reasons already discussed. However, change must be intertwined with critical reflection. The opportunities that SNSs and social media platforms now offer music learning, teaching, and performance - are already mindboggling compared to what was available ten years ago; we can only continue to imagine and envision and what may be coming in the near future. The below wise words from Henry Jenkins both encapsulate and serve as cautionary advice for us as we proceed into the 21st century:

As the Web has become routinized, and as interacting with others in digital places and spaces no longer seems routine, surprising or unfamiliar, we've seen far too few opportunities to reflect together on what kind of world is emerging here. (Jenkins, in James 2014, xxiii)

Thank you to the ACT Editors for offering us a platform and "place" to do just that.

\begin{abstract}
About the Author
Janice Waldron is an Associate Professor of Music Education at the University of Windsor. Her research interests include: informal music learning practices, online music communities, social media and music learning, vernacular musics, and participatory cultures. Waldron is published in multiple national and international journals and is the author of several book chapters in the field of music education. She serves on the editorial boards of Action, Theory and Criticism in Music Education, The International Journal of Music Education, The Journal of Music, Education, and Technology, T.O.P.I.C.S, and was named the 2012 "Outstanding Researcher: Emerging Scholar" at the University of Windsor.
\end{abstract}

Waldron, Janice. 2018. Questioning $20^{\text {th }}$ century assumptions about 21st century practices. Action, Criticism, and Theory for Music Education 17 (1): 97-113. doi:10.22176/act17.1.97 


\section{References}

Anderson, Chris. 2006. The long tail: Why the future of business is selling less of more. New York: Hyperion.

Banjo Hangout, main website page. http://www.banjohangout.org, accessed Sept 4, 2011.

Blanton, Christine. 2016. Pathways to learning: The musical journeys of five adult fiddle players. Unpublished doctoral dissertation, University of North Carolina, Greensboro.

Brewer, Wesley D., and David A. Rickels. 2014. A content analysis of social media interactions in the Facebook band directors group. Bulletin of the Council for Research in Music Education 201: 7-22.

Burnard, Pamela. 2012. Musical creativities in practice. Oxford UK: Oxford University Press.

Cawley, Jessica. 2013. The musical enculturation of Irish traditional musicians: An ethnographic study of learning processes. Unpublished doctoral dissertation, University College Cork.

Cayari, Christopher. 2016. Virtual vocal ensembles and the mediation of performance on YouTube. Unpublished doctoral dissertation, University of Illinois.

Cayari, Christopher. 2011. The YouTube effect: How YouTube has provided new ways to consume, create, and share music. International Journal of Education and the Arts 12 (6): 1-28.

Cian, Marco. https://www.instagram.com/marco cian/, retrieved April 12, 2016.

Gibson, William. https://en.wikiquote.org/wiki/William_Gibson retrieved April 14, 2015.

Harrison, Anthony Kwame. 2014. "What happens in the Cabin ...": An arts-based autoethnography of underground hip hop song making. Journal of the Society for American Music 8 (1): 1-27.

Jenkins, Henry. 2014. Forward: What were they thinking? In Disconnected: Youth, New Media and the Ethics Gap, by Carrie James, xiii-xxix. Boston, MA: The MIT Press.

Waldron, Janice. 2018. Questioning $20^{\text {th }}$ century assumptions about 21st century practices. Action, Criticism, and Theory for Music Education 17 (1): 97-113. doi:10.22176/act17.1.97 
Kruse, Nathan, and Kari Veblen. 2013. Music teaching and learning online. Considering YouTube instructional videos. The Journal of Music, Technology and Education 5 (1): 77-87.

Lanier, Jaron. 2013. Who owns the future? New York: Simon and Schuster.

Michielse, Maarten, and Heidi Parrti. 2015. Producing a meaningful difference: The significance of small creative acts within online participatory music practices. The International Journal of Community Music 8 (1): 41-57.

Miller, Daniel. 2011. Tales from Facebook. Cambridge UK: Polity Press.

Online Academy of Irish Music, main website page http://www.oaim.ie/index.php?option $=$ com content\&view $=$ article\&id $=46 \&$ Itemid $=53, \quad$ retrieved Oct 18, 2015.

O'Flynn, John. 2015. Strengthening choral community: the interaction of face-toface and online activities amongst a college choir. International Journal of Music Education Special Issue: Music Learning, User-generated Content, and Participatory Culture.

Palmquist, Jane, and Gail Barnes. 2015. School orchestra and string teachers Facebook group: An online community of practice. International Journal of $\mathrm{Mu}$ sic Education Special Issue: Music Learning, User-generated Content, and Participatory Culture.

Paparo, Stephen, and Brent Talbot. 2014. Meanings of participation in virtual choirs and implications for teacher education. Paper presented at the The $\mathrm{Na}$ tional Association for Music Education Biennial Conference, St. Louis, Missouri.

Partti, Heidi, and Sidsel Karlsen. 2010. Reconceptualising musical learning: New media, identity and community in music education. Music Education Research 12 (4): 369-82.

Peppler, Kylie. 2017. Interest-driven music education: Youth, technology, and music making today. In The Oxford handbook of technology and music education, edited by S. Alex Ruthmann and Roger Mantie, 191-202. New York: Oxford University Press.

Pitts, Stephanie. 2012. Chances and choices: Exploring the impact of music education. Oxford, UK: Oxford University Press.

Rainie, Lee, and Wellman, Barry. 2012. Networked. Cambridge MA: MIT Press.

Waldron, Janice. 2018. Questioning $20^{\text {th }}$ century assumptions about 21st century practices. Action, Criticism, and Theory for Music Education 17 (1): 97-113. doi:10.22176/act17.1.97 
Salavuo, Miikka. 2008. Social media as an opportunity for pedagogical change in music education. Journal of Music, Technology and Education 1 (2): 121-36.

Salavuo, Miikka. 2006. Open and informal online communities as forums of collaborative musical activities and learning. British Journal of Music Education 23 (3), 253-71.

Salavuo, Miikka, and Päivi Hakkinen. 2005. Informal online communities as music learning environments. Case: mikseri.net. Musiikki 1 (2): 112-38.

Schneier, Bruce. 2015. Data and Goliath: The hidden battles to collect your data and control your world. New York: W. W. Norton.

Sewell, Amanda. 2014. Paul's Boutique and Fear of a Black Planet: Digital sampling and musical style in hip hop. Journal of the Society for American Music 8 (1): $28-48$.

Strachan, Ian. 2010. The creative destruction of the "winner-take-all" society? Property rights and the economics of the long tail in the music industry. Unpublished doctoral dissertation, Colorado State University.

The Session main page. https://thesession.org, retrieved April 14, 2016.

Van Dijck, Jose. 2013. The culture of connectivity: A critical history of social media. Oxford, UK: Oxford University Press.

Waldron, Janice. 2016. An alternative model of music learning and 'last night's fun1': Participatory music making in/as participatory culture in Irish traditional music. Action, Criticism, and Theory for Music Education 15 (3): 86112.

Waldron, Janice. 2013a. User-generated content, YouTube, and participatory culture on the Web: Music learning and teaching in two contrasting online communities. Music Education Research 15 (3)L 257-74.

Waldron, Janice. 2013b. YouTube, fanvids, forums, vlogs and blogs: Informal music learning in convergent on and offline music community. The International Journal of Music Education 31 (1): 91-105.

Waldron, Janice, and Patricia Hopper. in press. Converging contexts: Music learning and teaching at the Online Academy of Irish Music's offline summer school, Liscannor, Ireland. In Proceedings of the ISME commission for community music activity: CMA XXXI, edited by Mary Cohen, Salvadore, Bahia, Brazil.

Waldron, Janice. 2018. Questioning $20^{\text {th }}$ century assumptions about 21st century practices. Action, Criticism, and Theory for Music Education 17 (1): 97-113. doi:10.22176/act17.1.97 
Waldron, Janice. 2011. Locating narratives in postmodern spaces: A cyber ethnographic field study of informal music learning in online community. Action, Criticism, and Theory in Music Education 10 (2): 32-60.

\section{Notes}

${ }^{1}$ I paraphrased Gibson's words here-his actual quote is "The future is already here-it's just not very evenly distributed" (https://en.wikiquote.org/wiki/William_Gibson).

2 I think this question possibly confuses music making with commodification, and which I think is the bigger concern.

3 YouTube is a good example of this from my own experiences presenting my research. I knew I was onto something when I gave my first conference paper on YouTubes, online communities, and music learning in 2009, because, after I was finished, a skeptical music education researcher raised her hand, emphatically pronouncing that, "I just don't believe people learn music that way" [i.e., informally, using Internet resources and YouTubes]. Research states otherwise.

4 I say "made" instead of composed because of the prevalence of "pre-made" digital samples used in a number of different music genres.

5 Examples include online participatory remix practices (Michielse and Parrti), online instrumental hip hop music (Sewell, 2014) and groups like Tw1tterBand, "a group of 11 people who have never met in person but who share an interest in music and philanthropy, formed a band through the social media network, Twitter, and released singles and videos [through YouTube and Soundcloud] that have helped raise money for charitable organizations" (http://ohotame.musedlab.org/t/kyliepeppler-indiana-university-usa/26).”

${ }^{6}$ Chris Anderson (2006) defined the term long tail to describe a retailing strategy that sells a large number of different items of which each sell relatively small quantities, but that all together represent a significant portion of items sold in total.

7 Marco is his real name-he specifically requested that I use it because of his growing fame as an instrumental hip hop producer.

8 In this, Marco's story is reminiscent of participants from both Pitt's 2012 work and Burnard's 2012 book on musical creativities.

9 How popular musicians learn-orally/aurally, through observation, sometimes supplemented with skeletal notation systems like $\mathrm{TAB}$ - has remained the same as when Green first codified vernacular learning styles as a "practice" in 2002. How-

Waldron, Janice. 2018. Questioning $20^{\text {th }}$ century assumptions about 21st century practices. Action, Criticism, and Theory for Music Education 17 (1): 97-113. doi:10.22176/act17.1.97 
ever, what has changed significantly since Green's 2002 study is the easy accessibility to and the sheer amount of online learning resources and artifacts available to learners due to the omnipresence of networked digital technologies and social media/networking systems; I label this instant availability to a multitude of online resources as "informal music learning practices 2.0." Specifically, learners with a computer and an Internet connection can now: 1) "Pick up," via networked technologies and social media/networking systems, resources, tools, user-generated content (such as YouTubes and mp3s) at any time in any number of diverse musical genres. Hard artifacts are no longer necessary and cloud storage makes for easy safekeeping and collaboration, and, 2) Locate and join a networked online community of learners for support, information, discourse, and collaboration. Because online music communities often overlap with corresponding offline ones, this can lead to "real life" opportunities for connecting, playing/performing, and music learning and teaching.

${ }^{10}$ Instrumental hip hop is a smaller and more specialized genre of hip hop that uses instrumental tracks only (Harrison, 2014).

${ }^{11}$ Marco is an instrumental hip hop producer-a sub-genre of hip hop-and differs from mainstream hip hop in that it draws on classical Western art music norms in referencing and creating musical "memes." Thus knowledge of Western art music and music theory is valuable and prized among instrumental hip hop composers (Harrison 2014).

12 "Producing beats" is hip hop slang for composing tracks made from sound samples, which are then "endlessly manipulated and layered into musical collages" (Harrison 2016, 36).

13 Jose Van Dijck defines a "culture of connectivity" as all platforms being connected all the time using all possible connections on the Web (2013).

Waldron, Janice. 2018. Questioning $20^{\text {th }}$ century assumptions about 21st century practices. Action, Criticism, and Theory for Music Education 17 (1): 97-113. doi:10.22176/act17.1.97 